\title{
Association of School Absence with Air Pollution in Areas around Arterial Roads
}

\author{
Kuniyoshi Makino
}

\begin{abstract}
Association of school absence with air pollution from suspended particulate matter (SPM) and nitrogen dioxide was analyzed in areas around arterial roads for five years, from 1993 to 1997. The prevalence of absence was calculated using the data for school absence in two schools around arterial roads, one of which is near a crossing (Sch.A), and the other is adjacent to an arterial road (Sch.B). Although the results from annual correlation analyses did not indicate common findings for five years or in the two schools, the prevalence of absence correlated positively with SPM, nitrogen dioxide, or relative humidity, and negatively with atmospheric temperature. As the results from multiple regression analyses, atmospheric temperature in Sch.A was adopted as the optimum explanatory variable, whereas SPM and relative humidity were considered in Sch.B. Odds ratios for the prevalence of absence to SPM were elevated and were significant in Sch.B, when using a quintile method. The other odds ratios for the air pollutants were not significant, but exceeded 1 . When the data were classified by day of the week, significant associations of the prevalence of absence were observed with atmospheric temperature in Sch.A and with SPM in Sch.B. The slope of the regressive equations by day of the week became steeper with the day in Sch.B. SPM was weakly associated with the prevalence of absence in Sch.A and was closely associated in Sch.B according to the optimum variables selected from the multiple regression analyses by day of the week.
\end{abstract}

J Epidemiol, $2000 ; 10: 292-299$

school absence, air pollution, particulate matter, nitrogen dioxide, longitudinal study

\section{INTRODUCTION}

Exposure to high levels of particulate matter and nitrogen dioxide in ambient air is known to cause acute adverse effects on health of schoolchildren ${ }^{16}$. School absence is one of the adverse effects, and it was reported that a positive relationship was found between daily school absence and air pollutants, particularly particulate matter, in longitudinal studies ${ }^{7-11)}$. However, school absence is likely caused more frequently by reasons other than air pollution in Japan. The most common reason for school absence is.infectious diseases such as influenza ${ }^{12}$. Since the endemic season of such diseases is in December through March in Japan, it is very difficult to detect the effects of air pollution on school absence during this period. Therefore, the study design must be maturely considered to analyze an association of school absence with air pollution.
The following items were considered for study areas, study schools, study periods, air pollutants. statistical models and others for the longitudinal study design. 1) High levels of air pollutants must be monitored for the suitable study area. 2) There are monitoring stations near the schools. 3) The daily data for school absence can be obtained for the five full years of the decided preservation period of the data. 4) The time of exposure to air pollutants and months to examine the data are limited to raise sensitivity. 5) Some statistical models are used to analyze relationships.

\section{MATERIALS AND METHODS}

\section{Study Area}

The area around arterial roads was considered for the study on health effects of particulate matter. The Yamatocho cross-

Received August 14, 1999 ; accepted February 21, 2000.

Address for correspondence : Tokyo Metropolitan Research Laboratory of Public Health 3-24-1 Hyakunincho, Shinjuku-ku, Tokyo, 169-0073 Japan. 
ing in Itabashi-ku, Tokyo, was focused on for the concentration of particulate matter. One of the roads on the crossing is Loop 7, and the other is the road combined with the Nakasendo Road and the 5th line of the Tokyo Metropolitan Expressway (Figure 1). There are two measuring stations of the Environmental Protection Bureau of Tokyo in the area. One of the stations near the crossing is called the station of automobile exhaust (Site A). The annual mean concentration of suspended particulate matter (SPM) measured in this station $\left(93 \mu \mathrm{g} / \mathrm{m}^{3}\right)$ was the highest in the stations of automobile exhaust in Japan, according to the data from 1993 to 1996. The other, which is south about 800 meters along the Nakasendo Road and 100 meters from the road, is called the general station (Site B). Similarly, the concentration of SPM in this station $\left(65 \mu \mathrm{g} / \mathrm{m}^{3}\right)$ was also the highest among the general stations in Japan for the same period. There is an elementary school near each of the stations. One of the schools is located about 110 meters southeast of Site A (Sch. A). The other is adjacent to the road and Site B (Sch. B).

Residential areas of schoolchildren were shown in Figure 1. Both two areas are classified into a commercial area in Tokyo, where residential districts intermingle with business districts. The residential area in Sch. A is only 0.16 square kilo-meters, where there are some shopping districts along some streets. On the other hand, the residential area in Sch. B is 0.36 square kilo-meters. Although there are some shopping districts, the rate of residential districts of the residential area is larger in Sch. B than in Sch. A.

\section{Data for school absence and environmental factors}

Data by day for school absence were obtained from the two elementary schools for the five years from 1993 to 1997. The absence data for the four months from December to March were not used to analyze the relationship between the preva-

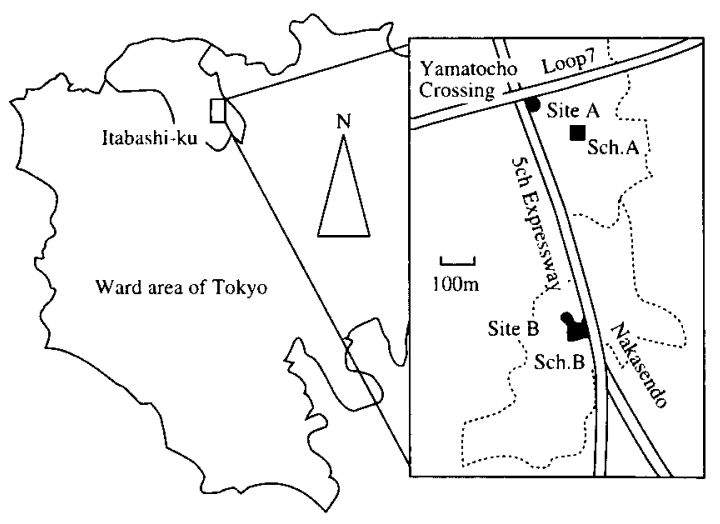

Figure 1. Study area included two schools $(\square)$, two monitoring sites $(\mathbf{)})$ and two residential areas of schoolchildren [ [.......... $]$. lence of absence and the concentrations of particulate matter and nitrogen dioxide. The number of absences rapidly increased for those four months because of epidemic diseases such as influenza, or other reasons such as household circumstances, in every year. The absence data of the days following holidays were not also used, for the number of absences on those days is higher than on other days.

As the environmental factors, the following four factors were selected. Data for daily mean concentrations of SPM and nitrogen dioxide were obtained in the two stations for the five years from 1993 to 1997 . Similarly data for meteorological factors such as atmospheric temperature and relative humidity were obtained in the station of Site B. Twelve- hour means from eight A.M. to eight P.M. were calculated for each of these data in consideration of outdoor behavior of children.

\section{Statistical Analysis}

Statistical analyses were separately conducted for the two schools/stations. The data of school absences in the day corresponded to air pollution or meteorological factors of the previous day when there is no time lag of days. Linear regression models were used to analyze the prevalence data, whereas explanatory variables were one or some of SPM, nitrogen dioxide, atmospheric temperature, and relative humidity. However, the two concentrations in both sites could not be directly compared as exposure indices. Sch.A is not adjacent to Site A, while Sch.B is adjacent to Site B. In this analysis, the statistical analyses were conducted by year, and time lag of days was examined up to three days, using correlation analyses. Logistic regression and Poisson regression models were also used for reference. Auto-correlation analyses between the school absence data were examined for a week, since there is probability of dependence on a day of the week for school absence. In addition, odds ratios from the multiple logistic model were examined by using the quintile method. The first quintile by frequency from lower concentrations of air pollutants was applied to the control group through the total study period.

In order to study the effects of a day of the week on the relationship between the prevalence of absence and air pollutants or meteorological factors, regression analyses were conducted by day of the week through the total study period. When the explanatory variables were plural, selection of the optimum variables was decided by AIC (Akaike's Information Criterion) statistics.

\section{RESULTS}

A summary of the data was presented in Table 1 for the fiveyear study period, but the data for air pollutants were not included for the duration of summer vacation (from July $21^{\text {ts }}$ to August $31^{*}$ ) or holidays. Numbers of schoolchildren were between 154 and 190 in Sch.A and between 380 and 458 in 
Sch.B for the five-year study period. Annual mean concentrations of SPM by year were between 81.7 and $120.9 \mu \mathrm{g} / \mathrm{m}^{3}$ in Site $A$ and between 49.0 and $80.2 \mu \mathrm{g} / \mathrm{m}^{3}$ in Site B during the study period. Similarly, annual means for prevalence of absence were between 1.5 and $2.1 \%$ in Sch.A and between 1.5 and $1.7 \%$ in Sch.B. Although there was little difference between total means of the prevalence of absence $(1.9 \%$ in Sch.A and $1.7 \%$ in Sch.B), variance of the prevalence of absence was significantly larger in Sch.A than in Sch.B $(p<0.05)$. This statistical result may have been caused by the difference of the number of schoolchildren, because statistical power is dependent on sample number. Annual means of atmospheric temperature were between 17.8 and $19.8 \mathrm{C}$ and means of relative humidity were between 67.3 and $74.0 \%$ in the five-year study period.

The prevalence of absence was significantly correlated with SPM, nitrogen dioxide and atmospheric temperature in Sch.A (Table 2). SPM, nitrogen dioxide, and relative humidity were correlated positively, and atmospheric temperature was negatively in some significant cases. Atmospheric temperature

Table 1. Summary of data for the prevalence of absence in Sch.A and Sch. B, and the environmental factors in Site A and Site B.

\begin{tabular}{|c|c|c|c|c|c|c|c|c|c|}
\hline \multirow{2}{*}{ Year } & \multirow{2}{*}{ Item } & \multirow{2}{*}{$\frac{\text { Sch.A }}{\text { Prev. }}$} & \multicolumn{2}{|c|}{ Site A } & \multirow{2}{*}{$\begin{array}{c}\text { Sch.B } \\
\text { Prev. }\end{array}$} & \multicolumn{2}{|c|}{ Site B } & \multicolumn{2}{|c|}{ Site B } \\
\hline & & & SPM & $\mathrm{NO}_{2}$ & & SPM & $\mathrm{NO}_{2}$ & Temp. & Hum. \\
\hline \multirow[t]{6}{*}{1993} & Mean & 2.0 & 118.5 & 71.5 & 1.5 & 49.0 & 42.0 & 17.9 & 73.5 \\
\hline & $\mathrm{SD}$ & 0.7 & 50.3 & 20.1 & 0.4 & 18.4 & 16.0 & 4.7 & 14.8 \\
\hline & Maximum & 3.7 & 312.2 & 129.2 & 3.5 & 176.6 & 97.6 & 27.2 & 98.3 \\
\hline & Minimum & 0.0 & 25.6 & 25.3 & 0.0 & 14.1 & 12.8 & 8.3 & 40.4 \\
\hline & Range & 3.7 & 286.6 & 103.8 & 3.5 & 162.5 & 84.8 & 18.9 & 57.9 \\
\hline & Days & 125 & 125 & 125 & 122 & 122 & 122 & 169 & 169 \\
\hline \multirow[t]{6}{*}{1994} & Mean & 1.5 & 120.9 & 74.8 & 1.7 & 67.7 & 43.7 & 19.9 & 72.7 \\
\hline & SD & 0.9 & 44.3 & 20.9 & 0.7 & 26.2 & 12.6 & 5.4 & 11.8 \\
\hline & Maximum & 5.5 & 250.3 & 157.8 & 3.5 & 158.2 & 95.9 & 31.1 & 96.8 \\
\hline & Minimum & 0.0 & 24.2 & 15.5 & 0.0 & 18.3 & 9.8 & 7.2 & 45.1 \\
\hline & Range & 5.5 & 226.2 & 142.4 & 3.5 & 139.8 & 86.1 & 23.9 & 51.7 \\
\hline & Days & 125 & 125 & 125 & 126 & 126 & 126 & 168 & 168 \\
\hline \multirow[t]{6}{*}{1995} & Mean & 1.9 & 123.2 & 69.0 & 1.7 & 66.9 & 44.9 & 18.9 & 68.2 \\
\hline & SD & 1.3 & 50.2 & 17.2 & 0.8 & 29.9 & 13.2 & 4.7 & 14.0 \\
\hline & Maximum & 7.8 & 318.1 & 127.5 & 4.1 & 142.8 & 85.4 & 28.6 & 95.8 \\
\hline & Minimum & 0.0 & 34.7 & 26.6 & 0.0 & 15.9 & 15.6 & 7.9 & 26.2 \\
\hline & Range & 7.8 & 283.4 & 100.8 & 4.1 & 126.9 & 69.8 & 20.7 & 69.5 \\
\hline & Days & 128 & 128 & 128 & 127 & 127 & 127 & 169 & 169 \\
\hline \multirow[t]{6}{*}{1996} & Mean & 2.1 & 92.8 & 59.1 & 2.0 & 80.2 & 43.5 & 18.6 & 72.8 \\
\hline & $\mathrm{SD}$ & 1.5 & 39.9 & 15.6 & 1.0 & 29.1 & 11.9 & 5.3 & 13.9 \\
\hline & Maximum & 7.2 & 261.3 & 110.2 & 6.8 & 216.7 & 78.5 & 31.8 & 96.9 \\
\hline & Minimum & 0.0 & 14.2 & 18.0 & 0.5 & 21.8 & 7.1 & 6.7 & 40.4 \\
\hline & Range & 7.2 & 247.1 & 92.2 & 6.3 & 194.8 & 71.4 & 25.1 & 56.5 \\
\hline & Days & 121 & 121 & 121 & 120 & 120 & 120 & 169 & 169 \\
\hline \multirow[t]{6}{*}{1997} & Mean & 1.8 & 81.7 & 48.0 & 1.5 & 62.9 & 36.2 & 19.6 & 68.4 \\
\hline & SD & 1.2 & 32.3 & 13.9 & 0.7 & 25.7 & 11.1 & 4.9 & 15.6 \\
\hline & Maximum & 5.2 & 209.9 & 105.8 & 3.4 & 168.8 & 75.0 & 31.7 & 98.8 \\
\hline & Minimum & 0.0 & 30.0 & 13.8 & 0.3 & 19.4 & 10.8 & 9.0 & 28.8 \\
\hline & Range & 5.2 & 179.9 & 92.0 & 3.2 & 149.5 & 64.2 & 22.8 & 70.0 \\
\hline & Days & 105 & 105 & 105 & 120 & 120 & 120 & 168 & 168 \\
\hline \multirow[t]{6}{*}{ Total } & Mean & 1.9 & 109.1 & 66.6 & 1.7 & 66.1 & 43.3 & 19.2 & 71.3 \\
\hline & SD & 1.2 & 47.1 & 20.3 & 0.8 & 28.3 & 13.1 & 5.1 & 14.1 \\
\hline & Maximum & 7.8 & 318.1 & 157.8 & 6.8 & 216.7 & 97.6 & 31.8 & 98.8 \\
\hline & Minimum & 0.0 & 14.2 & 13.8 & 0.0 & 14.1 & 7.1 & 6.7 & 26.2 \\
\hline & Range & 7.8 & 303.8 & 144.0 & 6.8 & 202.6 & 90.5 & 25.1 & 72.6 \\
\hline & Days & 604 & 604 & 604 & 615 & 615 & 615 & 843 & 843 \\
\hline
\end{tabular}

Duration from April 6th to November 30th except for the duration of summer vacation, from July 21 st to August 31 st

Prev.:prevalence $(\%)$, SPM:suspended particulate matter $\left(\mathrm{mg} / \mathrm{m}^{3}\right), \mathrm{NO}_{2}:(\mathrm{ppb})$,

Temp.:temperature $\left({ }^{\circ} \mathrm{C}\right)$, Hum:humidity $(\%)$, Sch.A,Site A,Site B:see Figure 1 
showed significant correlation in three of the five years in Sch.A. However, results from correlation analyses by year could not find a certain tendency in the two schools for the five years. On the other hand, there was almost no difference among the three models for the correlation analysis. Therefore, the linear regression model was mainly selected in the following analyses. Besides, correlation coefficients between the two air pollutants were from 0.78 and 0.22 for the five years in the two sites. Though these correlations were all significant $(\mathrm{p}<0.001)$, the coefficients varied widely by year. Next, multiple regression analysis was conducted by year and selection of the optimum variables was performed by AIC sta- tistics (Table 3). Although a certain tendency could not be obtained, as the correlation analyses, atmospheric temperature in Sch.A and SPM and relative humidity in Sch.B were selected as the optimum variables in more than three of the five years and during the total period. In addition, multiple correlation analyses showed significant result in the four years from 1993 to 1996 in Sch.A, in the two years of 1995 and 1996 in Sch.B, and in the total period. Correlation coefficients calculated with time lag of days up to three days did not exceed the coefficients when there was no time lag of days. Furthermore, the auto-correlation coefficients by year for a week were not significant in all cases when the data for the school absence on

Table 2. Annual correlation analyses between the prevalence of absence and the environmental factors.

\begin{tabular}{|c|c|c|c|c|c|c|c|c|c|}
\hline \multirow{2}{*}{ Year } & \multirow{2}{*}{ Model } & \multicolumn{4}{|c|}{ Sch.A and Site A } & \multicolumn{4}{|c|}{ Sch.B and Site B } \\
\hline & & SPM & $\mathrm{NO}_{2}$ & Temp. & Hum. & SPM & $\mathrm{NO}_{2}$ & Temp. & Hum. \\
\hline \multirow[t]{3}{*}{1993} & Linear & $0.371^{* * *}$ & $0.359 * * *$ & 0.156 & 0.150 & 0.019 & 0.025 & 0.062 & 0.122 \\
\hline & Logistic & $0.370 * * *$ & $0.357^{* * *} *$ & 0.156 & 0.149 & 0.020 & 0.025 & 0.059 & 0.122 \\
\hline & Poisson & $0.388^{* * *}$ & $0.379 * * *$ & 0.151 & 0.171 & -0.004 & 0.004 & 0.065 & 0.076 \\
\hline \multirow[t]{3}{*}{1994} & Linear & 0.012 & 0.008 & $-0.297 * *$ & -0.057 & 0.032 & 0.039 & -0.009 & 0.082 \\
\hline & Logistic & 0.012 & 0.008 & $-0.299 * *$ & -0.058 & 0.031 & 0.038 & -0.009 & 0.082 \\
\hline & Poisson & 0.012 & 0.008 & $-0.229 * *$ & -0.020 & 0.046 & 0.089 & -0.011 & 0.094 \\
\hline \multirow[t]{3}{*}{1995} & Linear & -0.018 & -0.017 & $-0.242 * *$ & -0.013 & -0.073 & 0.013 & 0.027 & 0.123 \\
\hline & Logistic & -0.022 & -0.022 & $-0.243 * *$ & -0.013 & -0.075 & 0.010 & 0.016 & 0.116 \\
\hline & Poisson & 0.028 & 0.056 & $-0.219 * *$ & -0.014 & -0.091 & 0.010 & 0.087 & 0.067 \\
\hline \multirow[t]{3}{*}{1996} & Linear & 0.043 & -0.042 & $-0.175^{*}$ & -0.003 & $0.201 *$ & 0.117 & 0.003 & $0.237 * *$ \\
\hline & Logistic & 0.042 & -0.041 & $-0.178^{*}$ & -0.005 & $0.198^{*}$ & 0.118 & 0.011 & $0.240^{* *}$ \\
\hline & Poisson & 0.050 & -0.044 & -0.161 & 0.040 & $0.199 *$ & 0.132 & -0.045 & $0.213^{*}$ \\
\hline \multirow[t]{3}{*}{1997} & Linear & 0.024 & 0.059 & -0.104 & -0.070 & 0.002 & 0.023 & -0.029 & -0.143 \\
\hline & Logistic & 0.024 & 0.060 & -0.104 & -0.073 & 0.002 & 0.023 & -0.029 & -0.143 \\
\hline & Poisson & 0.029 & 0.041 & -0.093 & -0.029 & -0.010 & 0.029 & -0.034 & -0.119 \\
\hline
\end{tabular}

$*: \mathrm{p}<0.05,{ }^{* *} \mathrm{p}<0.01,{ }^{* * *}: \mathrm{P}<0.001$

Table 3. Annual multiple regression analyses for the prevalence of absence with environmental factors.

\begin{tabular}{lccccccc}
\hline & Year & SPM & $\mathrm{NO}_{2}$ & Temp. & Hum. & Const. & Mult.corr \\
\hline Sch. A \& & 1993 & 3.42 & 7.09 & & & 1.05 & $0.390^{* * *}$ \\
Site A & 1994 & & & -5.33 & & 2.58 & $0.263^{* *}$ \\
& 1995 & & & -7.38 & 1.32 & 2.58 & $0.270^{* *}$ \\
& 1996 & & & -5.62 & & 3.26 & $0.202^{*}$ \\
& 1997 & & & & 0.84 & 2.56 & 0.097 \\
& Total & & & -4.13 & & 2.68 & $0.173^{* * *}$ \\
\hline Sch. B \& & 1993 & & & & 0.57 & 1.05 & 0.121 \\
Site B & 1994 & 3.37 & & & & 1.67 & 0.093 \\
& 1995 & 5.61 & -4.71 & & 1.22 & 1.31 & $0.256^{* *}$ \\
& 1996 & 3.20 & & & 8.60 & 1.22 & $0.213^{*}$ \\
& 1997 & & & & -7.10 & 2.01 & 0.140 \\
& Total & 2.28 & & & 0.50 & 1.12 & $0153^{* * *}$ \\
\hline
\end{tabular}

Prev::\% SPM:mg/m², NO2:ppm, Temp: $\times 100 \mathrm{C}$, Hum: $\times 100 \%$

Selection of variables by AIC, *:p<0.05,**:p<0.01,***:p<0.001 
Monday were excluded.

The average concentrations for SPM of the first quintile were $53.3 \mu \mathrm{g} / \mathrm{m}^{3}$ in Site $A$ and $34.2 \mu \mathrm{g} / \mathrm{m}^{3}$ in Site B, and for nitrogen dioxide were $40.1 \mathrm{ppb}$ in Site A and 25.6 in Site B. The odds ratios exceeded 1 for the both air pollutants in both schools as shown in figure 2. However, significant results were not obtained in Sch.A. The odds ratios were 1.07 (confidence interval, CI; 0.90-1.27) for SPM and 1.01 (CI; 0.881.15) for nitrogen dioxide in the most polluted fifth quintile. On the other hand, the odds ratios were elevated with the levels of SPM in Sch.B and were significant in the fourth and fifth quintiles. They were 1.14 (CI; 1.02-1.31) and 1.19 (CI; 1.051.36), respectively.

Mean values of the data for school absence and environmental factors classified by day of the week were presented in Table 4. Although the meteorological factors hardly varied among the days of the week, the prevalence of absence apparently varied with the day in both schools. The prevalence of absence decreased from Monday to Wednesday, and became flat after that. On the other hand, the lowest concentrations of air pollutants were found on Sunday. According to the results from the correlation analyses by day of the week (Table 5), SPM was significantly correlated with Thursday in Sch.A and in most days of the week in Sch.B, but nitrogen dioxide was not on any day of the week. As for the meteorological factors, atmospheric temperature, which was correlated negatively, was more closely related to the prevalence of absence than relative humidity.

When the regression equations in the prevalence of absence to the SPM concentration by day of the week were examined in Sch.B (Figure 3), the slopes of the equations became steeper with the day of the week. Results from multiple regression analyses by day of the week indicated a close relationship between the prevalence of absence and the SPM concentration particularly, in Sch.B (Table 6).

\section{DISCUSSION}

Analyzing the tendency of school absence by grade may be interesting in a survey with a large number of children, as the
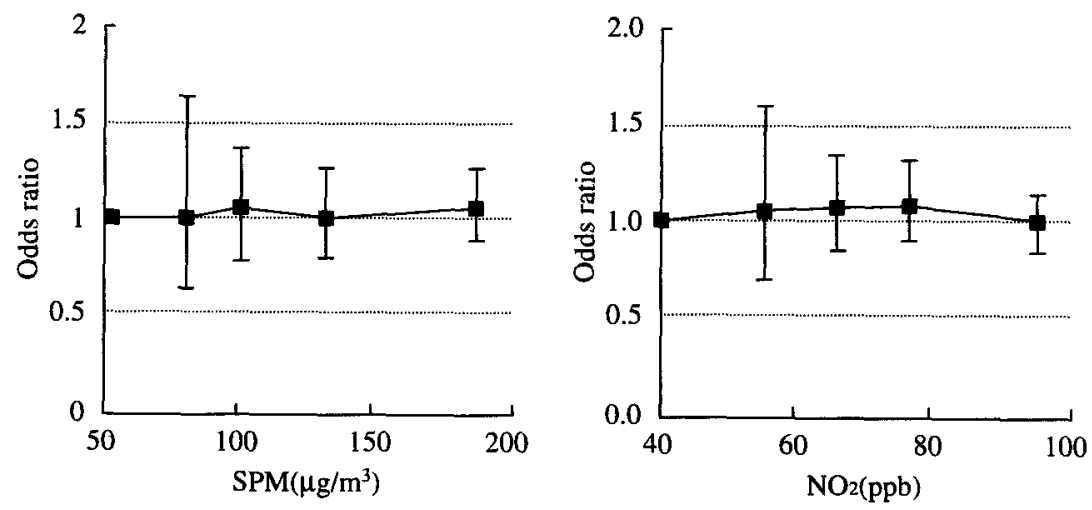

(a) Sch.A \& Site A
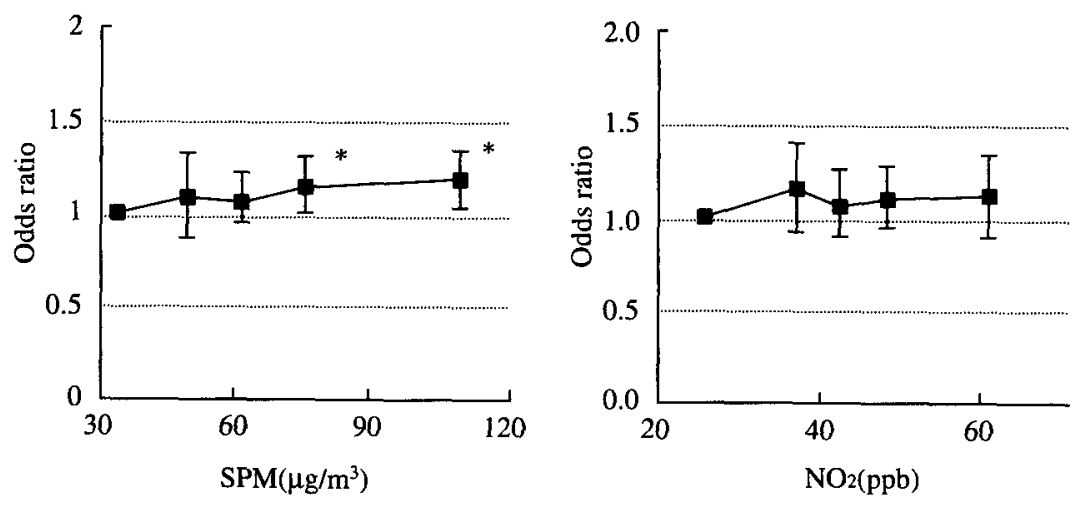

(b) Sch.B \& Site B

Figure 2. Odds ratios and the confidence intervals for the prevalence of absence to SPM and $\mathrm{NO}_{2}$ in using the quintile method $(*: \mathrm{p}<0.05)$. 
Table 4. Mean values for the prevalence of absence and the environmental factors by day of the week.

\begin{tabular}{|c|c|c|c|c|c|c|c|c|}
\hline \multirow{2}{*}{ Day } & \multirow{2}{*}{$\frac{\text { Sch. A }}{\text { Prev }}$} & \multicolumn{2}{|c|}{ Site A } & \multirow{2}{*}{$\frac{\text { Sch. B }}{\text { Prev }}$} & \multicolumn{2}{|c|}{ Site B } & \multicolumn{2}{|c|}{ Site B } \\
\hline & & SPM & $\mathrm{NO}_{2}$ & & SPM & $\mathrm{NO}_{2}$ & Temp & Hum \\
\hline Sun & & 62.2 & 46.3 & & 38.9 & 31.5 & 19.0 & 71.0 \\
\hline Mon & 2.2 & 101.1 & 70.5 & 2.0 & 58.1 & 46.5 & 19.0 & 70.5 \\
\hline Tue & 1.9 & 103.3 & 72.3 & 1.7 & 59.1 & 48.9 & 18.8 & 71.3 \\
\hline Wed & 1.7 & 98.9 & 71.8 & 1.6 & 57.1 & 48.5 & 18.9 & 71.2 \\
\hline Thu & 1.6 & 106.1 & 70.8 & 1.6 & 62.1 & 50.1 & 18.9 & 70.5 \\
\hline Fri & 1.6 & 101.3 & 73.4 & 1.5 & 60.7 & 50.5 & 18.9 & 70.9 \\
\hline Sat & 1.7 & 88.7 & 63.9 & 1.6 & 52.6 & 46.5 & 19.0 & 70.3 \\
\hline
\end{tabular}

Prev:\% SPM: $\mu \mathrm{g} / \mathrm{m}^{3}, \mathrm{NO}_{2}: \mathrm{ppb}$, Temp:C, Hum:\%

Table 5. Correlation analyses by day of the week between the prevalence of absence and the environmental factors.

\begin{tabular}{llrlll}
\hline \multirow{2}{*}{ Day } & \multicolumn{2}{l}{ Sch. A \& Site A } & & \multicolumn{2}{l}{ Sch. B \& Site B } \\
\cline { 2 - 3 } \cline { 5 - 6 } & SPM & NO2 & & SPM & NO2 \\
\hline Mon & 0.008 & 0.153 & & 0.171 & -0.120 \\
Tue & 0.153 & 0.066 & & 0.153 & -0.145 \\
Wed & 0.034 & -0.069 & & $0.343^{* * *}$ & -0.135 \\
Thu & $0.189^{*}$ & -0.017 & & $0.224^{* *}$ & 0.132 \\
Fri & 0.128 & 0.047 & & $0.246^{* *}$ & -0.052 \\
Sat & 0.000 & -0.075 & & $0.351^{* * *}$ & -0.101 \\
\hline Day & Temp & Hum & & Temp & Hum \\
\hline Mon & -0.103 & -0.042 & & -0.160 & 0.020 \\
Tue & -0.100 & 0.020 & & $-0.174^{*}$ & 0.091 \\
Wed & -0.161 & -0.017 & & $-0.240^{* *}$ & $0.193^{*}$ \\
Thu & $-0.236^{* *}$ & 0.128 & & -0.053 & $0.191^{*}$ \\
Fri & $-0.265^{* *}$ & -0.038 & & -0.147 & 0.132 \\
Sat & $-0.213^{*}$ & -0.003 & & $-0.190^{*}$ & 0.067 \\
\hline
\end{tabular}

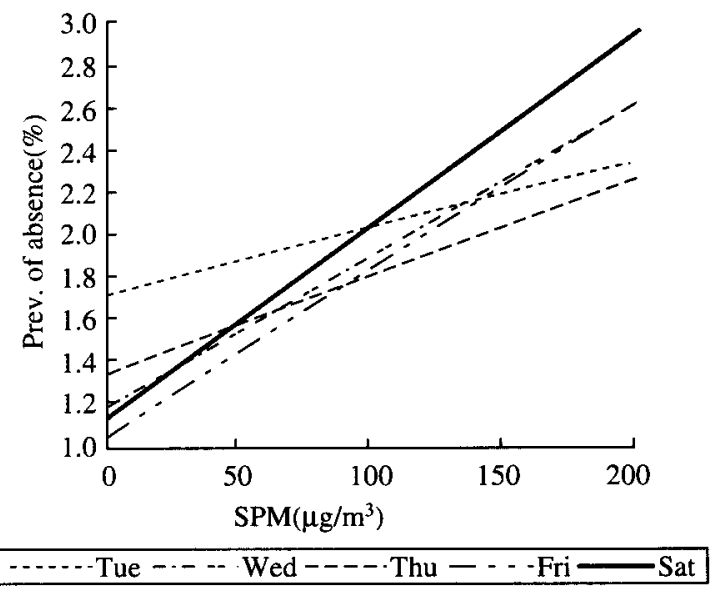

Figure 3. The regression lines for the prevalence of absence to SPM by day of the week in Sch.B.

Table 6. Multiple regression analyses by day of the week for the prevalence of absence with the environmental factors.

\begin{tabular}{lccccccc}
\hline & Day & SPM & $\mathrm{NO}_{2}$ & Temp. & Hum. & Const. & Mult.corr \\
\hline Sch. A \& & Mon & & 11.1 & & -4.82 & 2.52 & $0.264^{*}$ \\
Site A & Tue & 3.79 & & -2.92 & & 2.14 & 0.199 \\
& Wed & & & -3.24 & & 2.36 & 0.151 \\
& Thu & 3.59 & & -5.18 & 9.58 & 1.61 & $0.335^{* * *}$ \\
& Fri & 1.94 & & -4.98 & & 2.39 & $0.278^{*}$ \\
& Sat & & & -5.47 & & 2.94 & 0.216 \\
\hline Sch. B \& & Mon & 5.06 & -6.63 & -1.83 & & 2.35 & $0.263^{*}$ \\
Site B & Tue & 3.72 & -9.27 & & & 2.08 & $0.251^{*}$ \\
& Wed & 8.08 & -6.81 & & & 1.47 & $0.377^{* * *}$ \\
& Thu & 5.19 & -8.41 & & 9.16 & 1.03 & $0.320^{* *}$ \\
& Fri & 5.45 & -3.22 & & & 1.34 & $0.258^{*}$ \\
& Sat & 9.95 & -7.21 & & & 1.44 & $0.383^{* *}$ \\
\hline
\end{tabular}

Prev :\% SPM:mg/m³ $\mathrm{mO}_{2}: \mathrm{ppm}, \mathrm{Temp}: \times 100 \mathrm{C}, \mathrm{Hum}: \times 100 \%$ 
reason of absence is likely to vary with the grade. However, the obtained data could not be classified by grade or sex. The only information obtained from schoolmasters was that about $70 \%$ of absences involved $1^{\text {st }}$ and $2^{\text {nd }}$ grade children, and that there was no difference for the prevalence of absence between males and females. Classifications by grade might be not statistically suitable in this study, because sample numbers of the children were about 170 in Sch.A and about 400 in Sch.B. These sample numbers, which are not so large, become smaller when they were classified by grade. As a result, smaller samples might make the precision of analyses decrease.

In the present study, the data for the school absence in winter were excluded in consideration reasons different from air pollutants such as infectious diseases would increase the rate of school absence in winter. On the other hand, the prevalence of absence as well as levels of air pollutants would increase in winter. Although a close relationship between school absence and air pollution would be statistically found in winter ${ }^{10}$, it is difficult that to separate the effects of air pollutants are from those of infectious diseases.

The prevalence of absence by day of the week in both schools showed a coincidental tendency of the prevalence of absence to decrease from Monday to Wednesday, and become flat thereafter. This tendency was similar in the report by Ransome ${ }^{9)}$. It indicated that there was another reason of school absence in the former days of the week, although the reason was not clear.

Some statistical methods have been reported to elevate the precision or the sensitivity of analyses of the effects on health of air pollution ${ }^{13)}$. It is important to develop an accurate methodology in the present day and also in the future. Unfortunately, methodological progress could not be found in the study, though some statistical methods were also used in this study. As for the data selection, the significance of the correlation between the prevalence of absence and the concentration of SPM improved slightly by limiting exposure time to the twelve hours from eight A.M. to eight P.M ${ }^{14}$. When twenty-four hour measurement was used, the significant correlations as shown in Table 2 were not found. Some reports examined moving averages for a week, four weeks and others for the concentrations of air pollutants ${ }^{7,9,10)}$, but moving averages were not conducted in the present study because of lower concentrations on Sunday.

Higher levels of SPM and nitrogen dioxide in Site A than in Site $B$ do not indicate higher exposure levels of the air pollutants in Sch.A than in Sch.B, because Sch.A is not adjacent to an arterial road, but Sch.B is. In addition, Site $A$ is adjacent to an arterial road, but Site $B$ is not. The levels of the air pollutants in Sch.A would be lower than in Site A, whereas the levels in Sch.B would be similar or slightly higher than in Site $\mathbf{B}$. Total averages of SPM and nitrogen dioxide were $108.3 \mu \mathrm{g} / \mathrm{m}^{3}$ and $77.8 \mathrm{ppb}$ in Site $\mathrm{A}$, and $65.3 \mu \mathrm{g} / \mathrm{m}^{3}$ and $42.1 \mathrm{ppb}$ in Site B, respectively. According to the results from other surveys about SPM conducted in Site A and Sch.A for two weeks in summer and in winter in $1998^{15}$ ), the significant correlation was observed between SPM concentrations in Site A and in Sch. A. Both correlation coefficients in the two seasons exceed 0.88 ( $p<0.001$ ). In addition, the concentration of SPM in Sch.A was estimated to be a value between 53.0 and $66.3 \mu \mathrm{g} / \mathrm{m}^{3}$. As a result, the levels of SPM in Sch.A were estimated to be similar or slightly lower than in Sch.B. On the other hand, the levels of nitrogen dioxide in Sch.A were estimated to be roughly 65 ppb by applying the results from another report on the levels of nitrogen dioxide around arterial roads ${ }^{16)}$. The levels of nitrogen dioxide were estimated to be higher in Sch.A than in Sch.B. There was some difference of air pollution characteristics between Sch.A and Sch.B. This difference may have influenced the results from statistical analyses in the present study.

Annual wind direction were roughly divided into northern $(30 \%)$, eastern $(20 \%)$, southern $(19 \%)$ and other directions (31\%) in Site B in 1998. Since wind direction is inferred to be almost similar in the small area such as Figure 1 except for a building district, the concentrations would be strongly influenced in Sch. A by the northern road (the Loop 7) and in Sch. $B$ by the eastern road (the Nakasendo Road and the $5^{\text {th }}$ line).

\section{REFERENCES}

1. Hoek,G, Brunkreef,B. Effects of low-level winter air pollution concentrations on respiratory health of Dutch children. Environ Res, 1994; 64: 136-150

2. Neas,LM, Dockery,DW, Koutrakis,P, Tollerud,DJ, Speizer,FE. The association of ambient air pollution with twice daily peak expiratory flow measurements in children. Am J Epidemiol, 1995; 141: 111-122

3. Linn,WS, Shamoo,DA, Anderson, KR, Peng, RC, Avol,EL, Hackney,JD, Gong,Jr.H. Short-term air pollution exposures and responses in Los Angeles area schoolchildren. J Expo Anal Environ Epi, 1996; 6: 449-472

4. Timonen,KL, Pekkanen,J. Air pollution and respiratory health among children with asthmatic or cough symptoms. Am J Respir Crit Care Med, 1997; 156: 546-552

5. Agocs,MM, White,MC, Ursicz,G, Olson,DR, Vamos,A. A longitudinal study of ambient air pollutants and the lung peak expiratory flow rates among asthmatic children in Hungary. Int J Epidemiol, 1997; 26: 1272-1280

6. Braun-Fahrender,C, Vuille,JC, Sennhauser,FH, Neu,U, Kunzle,T, Glize,L, Gassner,M, Minder,C, Schindler,C, Varonier,HS, Wutrich,B. Respiratory health and longterm exposure to air pollutants in Swiss schoolchildren. Am J Respir Crit Care Med, 1997; 155: 1042-1049

7. Ponka,A. Absenteeism and respiratory disease among children and adults in Helsinki in relation to low-level air pollution and temperature. Environ Res, 1990; 52: 34-46

8. Kagamimori,S, Katoh, T, Naruse, Y, Kakiuchi,H, 
Matsubara,I, Kasuya,M, Kawano,S. An ecological study on air pollution: Changes in annual ring growth of the Japanese ceder and prevalence of respiratory symptoms in schoolchildren in Japanese reral districts. Environ Res, 1990; 52: 47-61

9. Ransome,MR, Pope II, CA. Elementary school absences and PM10 pollution in Utah Valley. Environ Res, 1992; 58: 204-219

10. Peters,A, Dockery,DW, Heinrich,J, Wichman,HE. Shortterm effects of particulate air pollution on respiratory morbidity in asthmatic children. Eur Respir J, 1997; 10: 872-879

11. Milligan,PJM, Brabin,BJ, Kelly,YJ, Peason,MG, Mahoney,G, Dunne,E, Heaf,D, Reid,J. Association of spatial distribution of childhood respiratory morbidity with environmental dust pollution. J Toxicol Environ
Health, Part A, 1998; 55: 169-184

12. Weitzman,M. School absence rates as outcome measures in studies of children with chronic illness. J Chron Dis, 1986; 10: 799-808

13. Pope II,CA, Schwaltz,J. Time series for the analysis of pulmonary health data. Am J Respir Crit Care Med, 1997; 154: S229-S233

14. Makino,K. Effects of school absence rates on suspended particulate matter. JJPH, 1998; 45: 739

15. Makino,K, Kurita,M. A study on variations of suspended particulate matter concentrations. J Soc Atmos Environ, 1999; 34

16. Makino,K, Fukuda,M, Onozuka,H. Effects of weather factors on concentration of nitrogen oxides around arterial roads. Ann Rep Tokyo Metr Res Lab PH, 1994; 45: 154 158 